\title{
Planning and Teaching an Undergraduate Course
}

\author{
Jumoke O. Ladeji-Osias \\ Department of Electrical and Computer Engineering \\ Morgan State University \\ Baltimore, MD 21251
}

\begin{abstract}
Planning a course involves many issues including choosing the objectives, scope and content, preparing a syllabus, developing lectures, laboratories, projects and assignments, and evaluation of students. Teaching the course is the implementation of the plan while developing a rapport with the students and monitoring classroom dynamics. Teaching requires adapting your plan to your current group of students and to the changing educational environment. This paper will discuss many aspects of planning and teaching an undergraduate course including a discussion on creating a student-centered environment through active and cooperative learning, and the use of rubrics and concept inventories. The emphasis will be on making incremental modifications to courses and assessing the impact of the changes.
\end{abstract}

Introduction

So you have been given the task of teaching a course.... Whether you are designing a new course, or teaching an existing course, there are many strategies to consider. You will find that prior to meeting your students, you will have many decisions to make and things to do. However, if your goal is to create a learning environment in which your students are expected to be active participants, you need to include some flexibility in your planning. The profile of your students may be different from your expectations or previous experiences; your plan will need to be adapted. Research on engineering education is continually changing; you may want to take advantage of some of the new work. This paper is divided into three sections: the first one will cover some of the details of planning a course, the second section will discuss teaching the course, and the third will suggest some next steps.

Planning a Course

Prior to making any decisions about your course, you will need to know your students' backgrounds. What are the prerequisites for the course? This can include college-level prerequisites and pre-college courses required of all students in the program. Does your program usually have only high-achievers or a mixture of abilities? These questions will determine the content and the level to which you teach. The first step in planning a course is to determine the objectives and content.

1. Course Objectives and Content: The decision on course objectives and content generally depends on where this course lies in the curriculum. Courses that are prerequisites for higherlevel courses may have an existing syllabus, which details the objectives and content. It is important to determine how much latitude will be available in changing the course content. Significant modifications to such courses may require consultation with other faculty who rely on certain topics being covered in that course. However, if you are to teach a new course or an elective you may be able to determine up to $100 \%$ of the course content. 
Course objectives can be used to determine course content. The objectives can be initially stated in general terms and then developed into more specific objectives. A well-defined list of course objectives should include the content to be covered and the abilities students are expected to demonstrate at the end of the course. This list should facilitate deciding what topics to cover and the scope of the coverage. The objectives for the courses may be stated in terms of correlation with Accreditation Board for Engineering Education (ABET) Criterion 3 (program goals and outcomes) to meet accreditation criteria [ABET, 2005]. Although the course objectives allow you to determine course content and areas of emphasis for tests, they can also be provided to students to indicate your expectations of them. The student's ability to meet the stated objectives can be used in evaluating your teaching ability.

One of the ways to develop course objectives is to use Bloom's taxonomy, which divides the cognitive domain into six levels: knowledge, comprehension, application, analysis, synthesis, and evaluation [Bloom, 1956]. This taxonomy can be used to determine that students are tested at different levels and are encouraged to develop higher lever skills such as synthesis and evaluation. For example, a student may be expected to

a. define Ohm's law

b. explain Ohm's law

c. apply Ohm's law to different resistors in a circuit

d. analyze a circuit using Ohm's law

e. design a circuit for a specific purpose using Ohm's law

f. assess the accuracy of a previously analyzed circuit

Each of these tasks requires the students to function at different levels of Bloom's taxonomy. McBeath Action verbs are a list of related verbs to each Bloom's level, and can be used in the development of course objectives [McBeath, 1992].

The criteria used to determine course content can include students' background, current trends in the field, course objectives, preparation for graduate school, number of design credits for ABET requirements, and available university resources. Regardless of how the course content is determined, it is important to decide what content to emphasize and how many class periods to spend on each topic. Deciding on content distribution will be important for the next step - selecting a format for your course.

2. Course Format: Now that you know what topics you want to teach, how will you deliver the material to the students? Lecture, laboratory, studio, field tours, or a combination? Will you and the students be in the same physical location or is there distance learning? Regardless of your delivery format, it is best to anticipate that students will have different learning styles and you may need to present your material in different formats. For example, you may need to put a topic in the context of the discipline to accommodate the global learners in your course. Your lecture may need to incorporate both visuals and text to be effective for visual and auditory learners alike.

The format that you select or has been assigned to your course should optimize student engagement. Remember falling asleep in long lecture courses? Remember skipping classes because you could learn it all from the textbook? How do you make yourself an important 
part of assisting students with learning the material? Is there a way to provide students with immediate feedback on errors? Can you keep them coming? One of the ways that has been shown to achieve this engagement is to create an active learning environment in your course. Students tend to remember most of the material presented at the beginning of a lecture but forget most of the material at the end. When the material is presented in segments, students tend to retain more information. Students should be expected to actively participate in the learning process through the use of in-class activities. This can include brainstorming with a neighbor, handing in a list of the points that need to be clarified for the next class period, or solving a semester-long problem. In addition, you may provide assignments that encourage group work. While all this activity may seem to take away from the time spent on the course material, active and cooperative learning have been shown to improve students' performance and retention. [Felder, 1995; Felder, 1998; Prince, 2004]

3. Course Textbook: The next step will be to select whether or not to have a mandatory course textbook. In first- and second-year courses, I strongly suggest having a course textbook or a photocopied packet of material and handouts, unless it is a design course. For these lower division courses, you will be teaching the fundamentals of the discipline and students may retain a good textbook for many years. For upper division courses, the decision on whether to use a textbook may depend on your approach in teaching the course.

Once a decision has been made to select a textbook, it is now time to find the best match. Many factors may determine the textbook you choose including covering course content with the same emphasis in your planning, format of the course, the look of the textbook (font, color, layout, use of figures), resources for students (homework exercises, online tutorials), resources for faculty (solution manual, PowerPoint lecture slides), price, and acceptability. If many of your students transfer to other institutions, it may be worth considering a textbook utilized by many faculty in your discipline. A textbook is essential if at least $60 \%$ of your material and assignments are available in one source. Once a textbook has been selected, use it as much as possible. Students tend to dislike purchasing a required textbook only to have it lying unused. Some of the textbook publishers offer the option of creating a custom book for your course, which includes sections from several stand-alone textbooks.

4. Course Syllabus: Once you have decided on what topics to cover, the delivery format of your course and the textbook, you are almost ready to create your syllabus. Your syllabus sets the tone for your course and provides students information on instructors, the course and your expectations of them. Also include information on course management software that will be used.

- Instructors: Important information about yourself and teaching assistants include name, phone number, office location, and office hours.

- Course: Include the course name and number, course description, objectives, meeting times, textbook(s), reference material, grading policy and course content. I like to provide my students with a tentative weekly listing of the topics, the assigned reading, homework, and dates for assessments. To generate this information, I sit down with a monthly calendar and list the topics and sections to cover each class period. The dates for homework, quizzes, examinations, and presentations are also 
included on the calendar. I leave two or three makeup days to provide some flexibility.

- Students: It is advisable to include how you handle late homework, missed classes, missed quizzes and examinations, cheating, and grade appeals. Some of these decisions may be governed by university policy, while others may be individual decisions. A makeup policy for missed work should be decided before class and adhered to. Some students have genuine emergencies, while others just take advantage of the system. It is best to be prepared for both. Discuss how often students are expected to check email or course management software if these means of communication will be used. Since you will be discussing this document with your students during the first week of class, it is best to establish the expectations.

5. Course Notes: Once you have decided on the course objectives, content, textbook and syllabus, it is time to develop the course notes.

- Lectures: For some texts, the publisher may make slides that include illustrations available to faculty who have adopted it. It is advantageous to have notes written in a format that makes it easily presentable to students, whether through overheads or writing on the board. For lower level courses, it is advised to follow the notation in the text, so students can focus on learning the material. Have your examples worked out, including all answers to eliminate time spent on calculations. Include extra examples in your notes, in case students have questions that can be easily illustrated to them. Your course notes should also include the active learning exercises for each topic. Having most of the details of your notes completed before the term starts will help you engage in minor editing the week before each class. If you opt to teach using an overhead projector, you may consider making your notes available to the students.

- Laboratories: Since laboratory equipment may determine the nature of exercises that can be conducted, ensure that no changes have been made to the available equipment. Be sure to test all laboratory instructions before each class especially if you are inheriting the material. You can also develop a list of common errors made by students on performing particular tasks. If the laboratory course is a co-requisite for another course, you will need to decide whether the topics should be covered in parallel, or if the laboratory should lead or trail the lecture course.

6. Evaluating Students: Most institutions require faculty to provide an indication of students' performance in their course. It is usually up to the faculty to determine the relative weight of each form of assessment. The most common forms of evaluating students include homework, quizzes, examinations, demonstrations, presentations, laboratory reports, posters, papers, and peer evaluation. Homework is sometimes viewed as serving two functions - providing an opportunity for the students to reinforce or practice the concepts, and as an assessment of progress. Homework that is not graded, or does not contribute to the course grade will probably not be completed by the students. One of the things to establish with students is how much collaboration, if any, is permitted on the homework. Assessment can be designed to include important topics that may not directly be related to the course topic such as ethics.

Your assessment should evaluate the student's ability to demonstrate competence in the areas of the course objectives. It may be helpful to the student for you to provide clear guidelines 
on your expectations for each level of performance. Are you interested in the ability to set up the equation correctly, or is getting the correct answer the only goal? This can be achieved through the use of rubrics. Rubrics provide students with a grid indicating the score to expect for different levels of work. This can assist students with the revision of their work. As faculty, we tend to have a mental rubric that we use when evaluating student work. We can look at the way a problem is solved, without verifying the answer, and decide whether it is A, $\mathrm{B}$, or $\mathrm{C}$ work before assigning points. Why not share the criteria with students to help them improve the quality of their work [McNeill, 1999; Mertler, 2001]?

One of the objectives of quizzes and tests is to discriminate very clearly between A, B, C, D, and $\mathrm{F}$ students. You will need to determine what percentage of your course students must master and to what extent as you assign your grades. Students tend to have access to old tests. This should be a factor in deciding how many new questions to include a test.

Teaching a Course

1. The First Week: On the first day of class, it is important to hand out and discuss your syllabus. This sets the tone for the rest of the semester. It is also important to determine who the students in your course are. You have made some assumptions about this in your planning; however, you may be able to fine-tune your course with data on the current class. Is the GPA distribution the same? Did the prerequisite courses cover the topics you expected? What is their current understanding of the topics in this course? Concept inventories are being developed for some subject areas to test students understanding of concepts. They are administered at the beginning and the end of the course to determine how student understanding has improved [Foundation Coalition, 2005]. The concept inventory can be used in several ways: to correct misconceptions, to assign students to groups, and to evaluate your effectiveness in covering certain concepts.

2. The Rest of the Term: It is important to establish the classroom dynamics. Remember students names - I work on first names initially, fewer to remember. React immediately to ringing cell phones, talking students, and other distractions. Politely ask students to stop. Consider asking them to leave if the behavior persists. As you engage in active learning activities monitor your time carefully; an increase in the volume in the classroom probably indicates that students are done. Consider what sort of rapport with the students is comfortable for you. Students may occasionally discuss more than their course work and you should be prepared for how to deal with this.

You have spent some time preparing your course notes, now you need to deliver this material to the students. Throughout the rest of the course, it is important to continually monitor your progress in covering your course content and to adjust accordingly using the course objectives. Is there a topic that turned out to take more or less time to cover? Did you find a better way to explain a particular topic? Make a note and modify the pace for the next time you teach the course. If a topic takes longer than expected, you might have to reduce the scope of another topic.

3. The Last Week of the Term: It is time to evaluate what worked, what can be improved and what needs to be eliminated. Trying to incorporate too many things at a time may prevent 
you from determining the effective changes. While student evaluations are an important part of assessing teaching, I believe it is also important to document one's ability to create an environment in which the students actually learn. You may not need to make major changes each semester; however, I suspect we never get to the point of having a perfect course.

\section{The Next Steps}

This article has discussed ideas to consider while planning and teaching your course. There are many things to consider, and you have a long career over which to try them. The first step is to download Teaching Engineering, a free publication that provides an excellent background on most of the topics discussed [Wankat, 2000]. It was the first book I used to improve my teaching and I believe it continues to serve me well. Next, visit Richard Felder's website [Felder, 2005] which includes extensive articles and resources on active and cooperative learning and learning styles. Between these two resources, you should be ready to start planning your course.

If you have inherited an existing course, some of the work may have been started - syllabus, textbook, course notes and old tests. You can then focus on fine-tuning the objectives, if needed, developing a detailed course schedule, and establishing an active learning environment. If you are developing a new course, you have no choice but to do everything!

Bibliography

1. ABET, Evaluation Criteria, http://www.abet.org/criteria.html, Accessed January 1, 2005.

2. Bloom, B.S. (Ed.) Taxonomy of educational objectives: The classification of educational goals: Handbook I, cognitive domain. New York, 1956.

3. Felder, R. M., “A Longitudinal Study of Engineering Student Performance and Retention. IV. Instructional Methods and Student Responses to Them." Journal of Engineering Education. 1995, 84(4): 361-367.

4. Felder, R. M., "A Longitudinal Study of Engineering Student Performance and Retention. V. Comparisons with Traditionally Taught Students.” Journal of Engineering Education. 1998, 87(4): 469-480.

5. Felder, R., Resources in Science and Engineering Education. http://www.ncsu.edu/felder-public/RMF.html Accessed January 1, 2005.

6. Foundation Coalition. Introduction to Concept Inventory. http://www.foundationcoalition.org/home/keycomponents/concept/introduction.html Accessed January 1, 2005.

7. McBeath, R., Ed., Instructing and Evaluation in Higher Education: A Guidebook for Planning Learning Outcomes: Education Technology, 1992.

8. McNeill, B., L. Bellamy, and V. Burrows, "A Quality Based Assessment Process for Student Work Products.” Journal of Engineering Education, 1999, 88(4): 485-500.

9. Mertler, C. A., "Designing Scoring Rubrics for your Classroom.” Practical Assessment, Research \& Evaluation, 2001, 7(25).

10. Prince, M., Does Active Learning Work? A Review of the Research. Journal of Engineering Education. 2004, 93(3):223-231.

11. Wankat, P. C., and F. S. Oreovicz, Teaching Engineering, McGrawHill Inc., New York, 1993, https://engineering.purdue.edu/ChE/News_and_Events/Publications/teaching_engineering/index.html Accessed January 1, 2005.

\section{JUMOKE O. LADEJI-OSIAS}

Jumoke (Kemi) Ladeji-Osias has been an Assistant Professor of Electrical Engineering at Morgan State University since 2001. She received her Ph.D. in biomedical engineering from Rutgers University in 2000. She teaches circuits, digital logic, and laboratory courses, and supervises senior design projects. She is married with three children Bunmi(5), Priscille(3), and Didier(1). 